\title{
Pedro de Berástegui:
}

\section{la química, el tabaco y la contrainsurgencia al servicio de las reformas borbónicas en la provincia de Venezuela (1779-1784)}

\author{
Pedro de Berástegui: \\ Chemistry, Tobacco and Counterinsurgency \\ at the Service of the Bourbon Reforms \\ in the Province of Venezuela (1779-1784)
}

\section{Alejandro Cardozo-Uzcátegui}

ORCID iD: https://orcid.org/0000-0002-4461-3285

Universidad Sergio Arboleda, Bogotá, Colombia

Pedro de Berástegui representa una expresión particular de las reformas del imperio llevadas a cabo en la Capitanía General de Venezuela: es obediente y devoto con las autoridades de la Capitanía, leal y comprometido con las misiones encomendadas, fueran estas científicas o militares. Visto de esta forma, se dará cuenta de otra comprensión tanto de la capitanía general venezolana en esta época de reformas y disturbios como de los distintos intereses e ideales que guiaron a estos funcionarios borbónicos del dieciocho.

Palabras Clave: Ilustración; Funcionario ilustrado; Reformas Borbónicas; Comuneros; Historia de la

Ciencia; Venezuela.

Pedro de Berástegui represents a certain manifestation of imperial reforms in the Captaincy General of Venezuela - he is obedient and devoted to the authorities of the Captaincy, loyal and committed to the scientific and military missions entrusted to him. From this perspective, the article introduces a new outlook on both the Venezuelan Captaincy General during a period of reforms as well as the unrest and the different interests and ideals that guided these Bourbon officials of the $18^{\text {th }}$ century.

KeYwords: Enlightenment; Enlightened Official; Bourbon Reforms, Comuneros; Province; History of Science; Venezuela.

Copyright: (C) 2021 CSIC. Este es un artículo de acceso abierto distribuido bajo los términos de la licencia de uso y distribución Creative Commons Reconocimiento 4.0 Internacional (CC BY 4.0). 


\section{Introducción}

El artículo deriva de una investigación histórica sobre la provincia venezolana, un área, en términos relativos, poco abordada en el periodo final del siglo XVIII, en el contexto de las expediciones científicas, la búsqueda de mejoras a la agricultura, las reformas fiscales y la resistencia que provocaron. En ese sentido, hemos reconstruido la trayectoria política y científica del navarro Pedro de Berástegui, químico, botánico y reformista ilustrado, quien se desempeñó en varios destinos de la Capitanía General de Venezuela.

Hemos revisado los fondos documentales del Archivo General de la Nación de Caracas, especialmente las colecciones de la Renta del Tabaco, Intendencia de Ejército y Real Hacienda, donde hay un flujo epistolar revelador sobre la labor científica de Berástegui respecto a las diferentes pruebas que el botánico le realizó al urao o trona (sesquicarbonato de sodio), rarísimo mineral que se encuentra en pocos yacimientos del mundo. Asimismo, en el Archivo General de Indias, dentro de la sección de Caracas, las cartas de Berástegui a las autoridades, o entre las autoridades que refieren a su labor directa e indirectamente, dan cuenta de su trabajo como espía - a veces devela a medias su identidad para pasar desapercibido y aprovecharse de ello- - en ocasiones como hombre de acción y otras, como analista e informante del proceso insurgente comunero (1781). La información que aportan los distintos remitentes funciona para reconstruir el momento de la crisis comunera y el entorno de dichos personajes a partir de estos egodocumentos, ${ }^{1}$ especialmente el de Pedro Berástegui y su paso por las diferentes responsabilidades que le correspondieron en el ámbito de las reformas borbónicas en la provincia de Venezuela. A través de sus cartas hemos podido situarlo en diversos lugares, así como saber de sus distintos proyectos en cada sitio.

De alguna forma, buena parte de sus proyectos coincidieron o estuvieron fatalmente conectados — como sus investigaciones sobre el mineral del urao- con sus ideas para el tabaco. Ambos rubros, tanto el tabaco como el urao convertido en chimó (carbonato de sosa cristalizado, una suerte de goma masticable embriagante), son parte del mismo control fiscal de la Corona, la Renta del Tabaco. Al mismo tiempo, las nuevas imposiciones fiscales y monopólicas del tabaco van a ser uno de los motivos de la rebelión

1 Dekker, 2002. 
comunera, hecho que también le va a corresponder enfrentar a Berástegui como funcionario del estanco y agente de confianza del intendente Ábalos.

Una primera parte del artículo abordará la misión científica de Pedro de Berástegui a los Andes venezolanos. A las afueras de la ciudad de Mérida realizó un análisis químico del mineral de urao de la laguna con el mismo nombre, con el fin de ensayar con muestras de tierra del fondo lacustre y saber qué beneficios podría aportar para el mejoramiento de la pólvora. Asimismo, Berástegui deseaba entender mejor las propiedades y potencialidades del producto que hacía famosa a la laguna: el chimó. Seguiremos los pasos de Berástegui en la tarea que dejó más huella en el paisaje agrícola y económico de los llanos venezolanos en la centuria venidera, que fue su profundo estudio del cultivo, almacenamiento y comercio del tabaco. En esta labor aplicó sus conocimientos botánicos y administrativos para maximizar las posibilidades de uno de los rubros más importantes del monopolio español en la provincia venezolana.

Por último, Berástegui demostró sus dotes de funcionario leal a la causa de sus superiores, José de Gálvez (en Madrid) y José de Ábalos (en Caracas), este último primer intendente de Venezuela y quien nombrará a Berástegui para diferentes cargos y misiones que no solo denotarán la confianza, sino que le acarrearán al botánico navarro responsabilidades superiores para lidiar tanto con la rebelión comunera como con las reformas para el cultivo, almacenamiento y comercialización de la apreciadísima hoja. No sobra advertir que en la última parte del artículo hemos profundizado un poco más, y manejado mayor volumen epistolar, por lo abundante del carteo de Berástegui, lo detallado que son sus notas sobre este trance y por lo sugerente que es percibir el cambio de enfoque que sufre el personaje, quien pasa, muy rápidamente, de la química a la contrainsurgencia: delaciones, enfrentamientos y contención de facciones sediciosas. Este tránsito existencial describe e identifica esta especie de tipología de los funcionarios borbónicos a quienes les correspondió lidiar con varios escenarios disímiles a lo largo de sus carreras en Hispanoamérica, durante un convulso instante de cambios profundos.

\section{De la botica a la Intendencia}

Pedro de Berástegui, natural de Eslava, en la comarca navarra de Sangüesa, fue boticario en Pamplona. En 1776 se le autorizó su viaje a la 
provincia de Venezuela como comisionado ilustrado de extrema confianza para José de Gálvez, ministro de Indias, y para José de Ábalos, primer intendente de Venezuela. Llamado para hacerse cargo de la botica de la Compañía Guipuzcoana de Caracas de Puerto Cabello — como reemplazo de su medio hermano, Pedro Labeaga—, el químico navarro no imaginó más eventos que la serena vida que podía dispensarle un oficio que venía haciendo desde Pamplona. ${ }^{2} \mathrm{Al}$ pie de un escritorio, a espaldas de un dispensario de reactivos, solventes, ácidos, cristales, drogas y compuestos de la farmacología del dieciocho, la exuberancia de los alrededores no ha podido escondérsele. Pedro de Berástegui gozaba de buena fama ante la mirada del intendente José de Ábalos, primero en presidir la institución ultramarina más activa y enérgica de la tardocolonia venezolana. ${ }^{3}$

Sin embargo, el apacible oficio como regente de la botica fue breve. En carta, José de Ábalos, una vez aprobado el «Nuevo plan de resguardo» ${ }^{4}$ fue taxativo: era necesario contar con individuos de «reconocida competencia y honorabilidad en los cargos del nuevo plan de resguardo», ${ }_{5}^{5}$ inmediatamente ordenó el nombre de Pedro de Berástegui como visitador general de la Renta del Tabaco. Este no fue su primer cargo de la mano de Ábalos, su rápido ascenso en el umbral de confianza del intendente fue notorio; Berástegui ya había hecho labores en la inteligencia y consejería militar de cara a la sublevación comunera, como veremos en la última parte.

\section{El mítico mineral}

En la primavera de 1781 la intendencia venezolana (creada en 1776) ordenó una misión científica para explorar las características del mineral del urao (apreciado como goma masticable y para mejorar la pólvora), curioso sedimento que en toda la América se encontraba solo en la Laguna de Urao en los Andes venezolanos. Llama la atención que la historiografía sobre las

2 Parra Pardi, 1997, I: 417-418.

3 Zubiri, 1988, 287-297.

4 El «Nuevo plan de resguardo» se implementó para el control del contrabando, especialmente de tabaco. En él se establecía aumentar el número de plazas militares y modificar los distritos para cada una de las rondas. A este proyecto se le sumó una política de reducción del gasto y una nueva estructura impositiva al tabaco. Andreo García, 1987, 101.

5 Carta de Pedro de Berástegui a su excelencia D. José de Ábalos, Intendente de la Provincia de Venezuela, Caracas, 5 de agosto de 1782, Archivo General de la Nación, Caracas (AGN), Renta del Tabaco, 21, f. 131. 
misiones científicas del dieciocho ${ }^{6}$ deje de lado — por modesto que haya sido - el viaje de Pedro de Berástegui por el occidente de la provincia venezolana, a sabiendas de que existían unas invariables relaciones entre el contexto político y cultural de la Ilustración española y europea y las prácticas concretas involucradas en la exploración botánica en América. ${ }^{7}$

De cara al atractivo que el urao prometía, Berástegui marchó a Mérida en mayo de 1781. Acaso extrañado por el silencio epistolar del visitador Berástegui, el intendente Ábalos pidió noticias suyas a Francisco Paula de Arteaga, comisionado de la Real Hacienda en aquella ciudad andina, quien con un dejo de intriga explicó que:

Y es que a pocos días de haber llegado a esta, continuó su marcha para la Laguna de Urao en donde me dicen está haciendo algunas operaciones para beneficiar lo que de ellas solicita, esto lo he sabido por fuera pues no le he merecido me haya dado la menor noticia en la corta distancia que hay que es poco más de medio día de camino. ${ }^{8}$

Por otro lado, también había molestia en Arteaga pues Berástegui, al parecer, convenció a unos indios para que se uniesen a su expedición bajo la promesa de «mayores ventajas y premios conforme a la cantidad del urao que estos indios le entregaran», contraviniendo las normas «según lo mandado» en cómo manejar el delicado asunto del citado mineral. Con su presencia, Berástegui le desordenaba la comarca a Arteaga.

Sin embargo, por su parte, Berástegui ya había escrito a Gálvez sobre el método usado para reconocer las propiedades del urao: cómo hacía diversos ensayos con montones de tierra separados y expuestos de distinta forma al medio «a fin de investigar de cual valora el salitre con más utilidad: el agua de la citada Laguna no es común, y las señales de color, olor y gusto, la caracterizan de particular, motivo suficiente para ponerla en tortura a fin de que manifieste lo que ahora nos oculta». ${ }^{9}$

Las reflexiones en torno a la dificultad de la investigación y los secretos velados de la naturaleza eran materia frecuente en las misivas. De esta forma el intendente Ábalos señalaba a Berástegui: «Previne a VM en otra ocasión que la naturaleza siempre ha sido muy rebelde en manifestar sus

6 Anes, 1998, 1-23.

7 Nieto, 2019, 55.

8 Carta de Francisco Paula de Arteaga, comisionado de la Real Hacienda, a su excelencia don José de Ávalos, Intendente de la Provincia de Venezuela, Mérida, 28 de junio de 1781, AGN, Intendencia de Ejército y Real Hacienda, t. XIII, fs. 309-310.

9 Carta de don Pedro de Berástegui a su excelencia D. José de Gálvez, Mérida, 3 de junio de 1781, AGN, Intendencia de Ejército y Real Hacienda, t. XIII, f. 171. 
secretos». Se trata del buen amigo que consuela al científico frustrado en su primer experimento, pues la extracción y ensayos del salitre y del urao aún no habían logrado los efectos pensados. Al final, lo anima a seguir:

Sin fiarse mucho de los primeros experimentos [...] una desconfianza ha modificado, y consumido el tiempo a los mejores principios, que después de infinito trabajo, se han hallado burlados con efectos muy contrarios a los principios que ya habían abrazado: pero sin abandonar sus proyectos han conseguido con la paciencia y fatiga muchos conocimientos que ignoraron los antiguos, cuya regla es necesario siga VM en lo concerniente a la su facultad para que en el modo posible sea fructífera su peregrinación. ${ }^{10}$

Concluida su misión, Berástegui aseguraba que nunca antes se había estudiado las cualidades minerales de la laguna de Urao hasta su comisión científica. El 25 de julio escribe desde Mérida sobre «lo tocante al examen de la Laguna que con el mayor tesón, y sin que habían experimentado en la ciudad y jurisdicción de Mérida [...] he examinado la Laguna con todo lo que en sí encierra, y sus vecindades, será testigo de esto una carga de salitre, y cinco de urao que al cuidado de Cabanie se conducen a la ciudad del Tocuyo». La misión al parecer se había logrado o, al menos, no había ido tan mal como en el quitapesares de la carta de Ábalos. Así pues, revelaba el químico que «el salitre es procedente de las tierras vecinas de la Laguna de Mérida, y a su agua, si este es como espero sale bueno para el efecto de la pólvora, haré con la mayor puntualidad un plan de forma que con el agua de dicha Laguna, y las tierras vecinas se pueda sacar con bastante utilidad cuando salitre de guerra». Era necesario someter a otras pruebas el material enviado al Tocuyo, e indicaba que «VM lo haga examinar por algún polvorista de su satisfacción». ${ }^{11}$ Finalmente, en dicha carta, deja saber el dato de su itinerario al informar al intendente que salió del pueblo de Las Lagunillas (Mérida) el 17 de julio y, ahora, le escribía (25 de julio) desde la ciudad de Trujillo de Venezuela: Tres meses de investigación y experimentos a las orillas de la mítica laguna.

De su periplo posterior sabemos por una carta del 7 de agosto del administrador de Real Hacienda de la ciudad de El Tocuyo, Francisco de Uriz, donde se informa que Berástegui se encontraba en esa ciudad. Precisamente, avisaba que se cumplía el encargo de Miguel Vizcaya de «entregar

10 Carta de José de Ábalos, Intendente de la Provincia de Venezuela a don Pedro de Berástegui, Comisionado Real de la Renta del Tabaco, Caracas, 19 de julio de 1781, AGN, Intendencia de Ejército y Real Hacienda, t. XIV, f. 149.

11 Carta de Pedro de Berástegui a don José de Ábalos, Intendente de la Provincia de Venezuela, Trujillo 25 de julio de 1781, AGN, Intendencia de Ejército y Real Hacienda, t. XIV, f. 217. 
una cama en mano propia» al químico. ${ }^{12} \mathrm{El}$ camino de Trujillo al Tocuyo se hacía en aquel momento con una escala en el pueblo de Carache, ${ }^{13}$ lo que sumaba unos 228 kilómetros, poco más de dos días de viaje, que no es poco tiempo para hacerlo por trayectos tan duros.

\section{El tabaco: ciencia del cultivo y sapiencia administrativa}

La reestructuración de la gobernación de Venezuela, entre los años de 1776 y 1777, sumó las provincias de Trinidad, Margarita, Cumaná, Guayana, Caracas y Maracaibo, nombradas en su conjunto como Tierra Firme. La creación en 1777 de la capitanía general supuso, en esencia, el nacimiento de Venezuela, ${ }^{14}$ no obstante, la erección de la intendencia en 1776 se considera el hito del «origen» ${ }^{15}$ político-administrativo-territorial venezolano. Esta idea se apoya en la autoridad del capitán general y del gobernador en relación a la figura del superintendente delegado de Real Hacienda, quien tendrá mando por encima de las otras dos autoridades que se circunscriben a la defensa y al gobierno. ${ }^{16} \mathrm{La}$ intendencia engloba mayores facultades cuando se encarga, entre otras cosas, del ámbito económico, recaudación fiscal, fomento y planificación del desarrollo del territorio que abarca; el intendente será el funcionario más polivalente para el programa reformador y centralizador. ${ }^{17}$ No se olvide que la intendencia de Ejército y Real Hacienda de Caracas será la primera de Suramérica. ${ }^{18}$

En tal sentido, una de las tareas principales que se le dieron al intendente fue el establecimiento del Estanco del Tabaco (1 de mayo de 1779) en las gobernaciones bajo su égida. ${ }^{19}$ La instauración del Estanco del Tabaco, para los habitantes entendidos y actores económicos de la provincia venezolana - ciertamente conmovidos con noticias como la de los colonos norteamericanos y con ese aire de rebelión que comenzaba a soplar para bien o para mal—, fue percibida con sospecha y aversión, además la institución

12 Carta de Francisco de Uriz a don José de Ávalos, Intendente de la Provincia de Venezuela, Caracas, 7 de agosto de 1781, AGN, Intendencia de Ejército y Real Hacienda, t. XIV, f. 281.

13 García Yépez y Rodríguez Rojas, 2010.

14 Briceño-Iragorry, 1989, 51.

15 Ver Andreo García, 1997, 237-257.

16 Andreo García, 1991.

17 Andreo García, 1989, 1508.

18 El 8 de diciembre de 1776 Carlos III firmó la real cédula de erección de la Intendencia de Caracas.

19 Arcila Farías, 1977, 7 
del Estanco fue asociada e imaginada para estas gentes como allegada de la Intendencia. ${ }^{20} \mathrm{El}$ pueblo llano fue menos subjetivo en su apreciación: ante el solo hecho de ver coartada su libertad de cultivo y comercio del tabaco asumió al Estanco con toda la animosidad posible.

La Corona intentaba, poco antes, justificar ante sus vasallos la creación del Estanco. En la cédula del 24 de junio de 1777 se deslinda una actividad natural - y privada - de agricultores y manufactureros para volverse una operación del Estado con la excusa de la urgencia de recaudación para afrontar la defensa de los mares y reinos americanos. De hecho, los gastos que incurrían en la defensa eran altos, la Real Hacienda apenas soportaba el continuo dispendio en transporte de tropas y suministros para reforzar las plazas principales de ultramar. Los años finales del setecientos fueron convulsos en la defensa de la América española. La creación del Estanco del Tabaco fue uno de los proyectos para sumar recaudación y formó parte de la reestructuración de la Hacienda imperial, que requería un fortalecimiento rápido del tesoro para soportar las cargas de la administración de la guerra, así como de la diplomacia frente a la amenazante Inglaterra. A la postre, este proyecto estaba soportado sobre los hombros de la joven intendencia.

La Corona definió las formas de amortiguar la carga que esto suponía, como posibilitar que los ayuntamientos escogieran la manera de pechar los impuestos (por el encabezamiento o limitando el cultivo del tabaco en terrenos que fueran estrictamente controlados por las autoridades del Estanco). Sin embargo, ambas fórmulas restringían el consumo, el cultivo, la venta del producto y su exportación. Este control encareció los costos de producción y consumo del fruto. El intendente, facultado por su experiencia en el lugar, sabría cómo discernir entre las particularidades y las costumbres locales para decidirse por la estrategia más conveniente. De nuevo será Pedro de Berástegui — como funcionario ilustrado - el comisionado para que la Intendencia tomara la estrategia más eficaz.

$\mathrm{Al}$ establecimiento del Estanco hubo oposición y debates en los cabildos. En el de Caracas acaeció una extendida discusión sobre la forma de tributarle a la Real Hacienda por medio de la presión del Estanco. Ya hemos anotado que la Corona dio dos posibilidades, entre el encabezamiento o «cabezón» —como se recoge en los documentos- y el del Estanco directamente; el encabezamiento era un impuesto a los agricultores tabacaleros que estos a su vez lo sumaban al precio final, siendo el consumidor quien

20 Izard, 22, 1972. Pacheco, 2008, 250-255. 
pagara el gravamen. Se excluía así a todos aquellos que no consumían tabaco. Por razones desconocidas, o al menos en debate pendiente, el cabildo caraqueño prefirió el Estanco. En Mérida, Pedro de Berástegui —nombrado por Ábalos visitador general de la Renta del Tabaco de la Intendencia- se enfrentó con los funcionarios cuando quiso aplicar las instrucciones del Estanco al chimó y al moó ${ }^{21}$ en el pueblo de Las Lagunillas, donde hizo sus investigaciones sobre el urao y el salitre.

Sin embargo, el alcalde de Mérida, Pascual María González, le torpedeó el mandato ocasionando un conflicto de atribuciones al que tuvo que sumarse la voz de los superiores de la gobernación y de la Real Hacienda. Berástegui le escribió al alcalde con contundencia: «No he practicado en la Laguna o pueblo, ni con su Cacique y demás justicias, más que aquello que me franquea mi comisión, y hallándome esta presentada a los jueces que corresponden, la debo llevar a debido efecto o hacer de su parte lo que pareciere y a quien corresponde». ${ }^{22} \mathrm{El}$ químico navarro había publicado un requerimiento el 7 de junio de 1781 donde ordenaba al corregidor de los indios de Las Lagunillas, Ramón Hernández, al alcalde mencionado y al cacique José Antonio Mercado, entre otros funcionarios locales, que le dieran toda la libertad de trabajar en la Laguna y sus alrededores, desde su llegada hasta su partida, así como entregarle todo el urao que los nativos pudieran extraer, pagándose como estaba establecido, y, de lo contrario, ejercería todo el peso de la ley. Una que vez se resolvió el altercado, el urao extraído de la Laguna pasaría por completo a la Administración de la Renta del Tabaco.

La principal contribución científica que se le atribuye a Berástegui no es otra que el perfeccionamiento de la elaboración del moó y del chimó, gracias a haber descubierto la mejor mezcla del urao en la laguna de Mérida utilizando las partes desaprovechadas del tabaco. Este beneficio maximizaba la cosecha de tabaco y además mejoraba la selección de las hojas, pues para el chimó y el moó se empezarían a utilizar, por la recomendación del químico navarro, los tallos, troncos, hojas menudas, los botones y cabezas que quedaban después de la recogida, destinando las mejores hojas al proceso del tabaco propiamente. Se perdería lo menos posible del desecho de la primera cosecha de tabaco, a la vez que se iba a mejorar la calidad del chimó y del moó con aquellos restos. Recuérdese que el tabaco de Barinas — conocido en Europa como el Varinas — llegó a ser el mejor y más

21 Chimó con menos carga de urao.

22 Arcila Farías, 1977, 29. 
consumido desde la península hasta Ámsterdam. Este testimonio histórico de 1841, el más temprano sobre el ilustrado navarro, sintetiza su legado:

Fue en 1781 que el químico español Pedro Verástegui, recorriendo el occidente, observó el uso que hacían de los ambires, perfeccionó su elaboración y enseñó a mezclar el urao de la laguna de Mérida y a aprovechar el tabaco inútil. En 2 de agosto del mismo año quedaron comprendidos en el sistema del estanco el mo el chimó y el urao. Por los estados comparativos, desde 1781 hasta 1801, resulta que un año con otro, la renta había producido más de medio millón de pesos líquidos. ${ }^{23}$

El sistema de propiedad de la tierra que pervivía en la provincia de Venezuela ya no se adecuaba con la velocidad que demandaba el cultivo del tabaco. El Estanco del Tabaco requería un dinamismo que las formas de explotar la agricultura en la provincia no iban a soportar. Lo que se había propuesto la administración imperial en extensión de tabaco cultivado no sería posible sin una rehechura del régimen de tenencia. Berástegui desaprobó las condiciones en que los campesinos tabacaleros labraban la tierra en Barinas y Guanare (zona occidental de los Llanos), la mayoría no era propietaria y se valía de pequeñas extensiones arrendadas que, mediante el trabajo personal, sin más mano de obra, pagaba el usufructo de la parcela, o mediante la misma cosecha. Esta precariedad impedía sembrar grandes extensiones de tabaco para satisfacer la demanda del monopolio. Berástegui criticó duramente las condiciones de estos campesinos pisatarios o arrendatarios, labriegos de unas tierras ajenas, en manos de poco más de doce propietarios. Estos extensos predios mantenían dentro, en extremas condiciones de privación operativa, a unos treinta campesinos intentando subsistir con escasísimas herramientas de labranza, métodos primitivos de siembra e ignorando todo respecto a la preparación del suelo.

Para Berástegui tales condiciones impedirían el desarrollo del rubro y, por ende, cumplir las metas de recaudación del nuevo modelo administrativo. Recomendó conceder líneas de crédito a los propietarios para asegurar la inversión, a la vez que ensayar fórmulas diferentes de negocio, como proveer parcelas de tierra - que no estuvieran en manos de privados-a los más diestros en materia de cultivo sin darles la propiedad de la tierra. Asistirlos económicamente desde el Estado pero como contratistas, no como pisatarios ni arrendatarios. Planteaba Berástegui que se les exigiera el cumplimiento de una cuota de producción de tabaco en relación proporcional a la tierra concedida, en calidad de contrato para vender la producción entera

23 Codazzi, 1841, 155. 
al Estanco. Así, el Estanco seleccionaba la tierra por recomendación de peritos de la Renta, se encargaba del servicio del agua necesaria, fijaba los límites y deslindes de esos terrenos, hacía los trabajos de deforestación y limpieza de los predios cultivables y levantaba cercados para deslindar con algún vecino privado - en caso de que lo hubiera-, evitando también el paso de ganado y personas, y así proteger las plantas de tabaco. Así establecía Pedro de Berástegui el modelo de explotación de la tierra para el tabaco en Venezuela, desde el génesis del monopolio hasta su abolición. ${ }^{24}$

\section{De la ciencia a la contrainsurgencia}

El regente de Santa Fe, dicen que escapó huyendo, y así de esta manera van pagando estos Lobos carniceros de Administradores, Alcabaleros, y Estanqueros, toda la crueldad que han usado con nosotros. A Maracaibo se han refugiado algunos, y otros para Caracas, y especialmente algunos Chapetones de España, y Extranjeros, pues sobre estos se descarga el golpe con más fuerza. ${ }^{25}$

El movimiento de los comuneros del Socorro fue una respuesta a la alta presión colonial de los impuestos y las alcabalas, medidas tributarias que tuvieron en Nueva Granada y Venezuela peso especial, como hemos señalado, por el aparato recaudador y monopólico de la Renta del Tabaco y la Intendencia, rediseños político-administrativos para recaudar más y gobernar con mayor presencia peninsular. La limitación del cultivo y comercio del tabaco unió en una suerte de causa común a sectores productivos más acomodados (hacendados y comerciantes) con la misma plebe, «el común». ${ }^{26}$ Acaso la rebelión de José Gabriel Tupac Amaru, o «el inca del Perú», como lo presentan varias veces en las relaciones epistolares, hizo de epicentro noticioso del levantamiento, pero no fue la única causa de una revolución que se iba a dar igualmente por el malestar, el empobrecimiento y la carestía que estaba provocando este afán de recaudación. ${ }^{27}$ El visitador

24 El más extenso análisis de Berástegui sobre la producción, almacenamiento y venta del tabaco se puede leer en su documento «Informe de Don Pedro Berástegui, sobre cultivo de tabaco en Guanare y Barinas, 1781. Dictamen de los terrenos de las ciudades Guanare, Barinas y sus respectivas jurisdicciones a efecto convendrá fomentar en ellas las siembras de tabaco al beneficio curaseca y otros». Recogido completo en Arcila Farías, 1977, 328-334.

25 Carta interceptada en Estanques, Mérida, de José Ignacio Molina a su compadre José Del Carmen Ramírez, Mérida 20 de julio de 1781, Archivo General de Indias, Sevilla (AGI), Caracas, 425.

26 Cardoza, 2015, 126.

27 Sería sugerente abrir nuevas discusiones sobre qué tanto el movimiento comunero estuvo influenciado por el levantamiento de Túpac Amaru (y no por agendas propias) y hasta dónde el origen del movimiento en Venezuela se puede ubicar solamente en el Socorro pues, aunque es el foco más investigado en el virreinato de la Nueva Granada, no fue el único. 
Juan Francisco Gutiérrez de Piñeros, enviado a Nueva Granada por Carlos III, escribió a José de Ábalos:

Parece que han trascendido las inquietudes a la Plata y Santa Cruz de la Sierra, y se dice que en ésta cometieron los amotinados la atrocidad de quemar vivo, en una hoguera que hicieron con el tabaco, al Director General de esta Renta en el Virreinato de Buenos Aires. Dios quiera que se apague cuanto antes este fuego y que contenidos y castigados los rebeldes no trascienda un ejemplo tan perjudicial a los demás países de América, pues los ánimos en todas partes son propensos a la imitación [...] aquí hemos tenido también una especie de alboroto en las Villas de Socorro y San Gil y parroquias inmediatas que por varios vecinos de ellas, que son los que llaman gente de color se tumultuaron contra las rentas del tabaco, aguardiente y alcabalas y para contenerlos y castigarlos ha salido ya un oidor con cincuenta soldados de la guardia del Virrey y algunos voluntarios y guardas. Se espera que no tenga consecuencias este suceso. $^{28}$

Al contexto de coacción tributaria que de hecho empobrecía a los pequeños productores y comerciantes, en especial a la población más vulnerable, se unía una situación de precariedad sostenida por la guerra contra Inglaterra (1779-1783). Esta coyuntura económica que en una mirada rápida pareciera que solo afectaba a la plebe, también tuvo eco en las clases más acomodadas. ${ }^{29}$ De hecho, uno de los principales promotores en el Socorro, Juan Francisco Berbeo Moreno, era propietario, tenía esclavos y era regidor del cabildo. En Zipaquirá (Nueva Granada) cerca de la frontera actual entre Colombia y Venezuela, se llegó a negociar la sublevación en mayo de 1781 a través de capitulaciones - que no implicaban la rendición de los comuneros - donde fundamentalmente se acordaba bajar o eliminar los nuevos impuestos inconsultos a la población, en especial, las tarifas de las contribuciones sobre el tabaco y el aguardiente. ${ }^{30}$ El virrey Flórez desconoció desde Cartagena de Indias el documento, por lo que el movimiento prosiguió, ahora con el chispazo del resentimiento por la engañifa.

En Mérida, el cabecilla de los «rebeldes y malcontentos» fue Domingo Contreras. El 10 de septiembre de 1781 ya se encontraba Contreras en Barinas invitando a las gentes y milicias a la revuelta. ${ }^{31}$ Los comuneros en

28 Carta del visitador real, don Juan Francisco Gutiérrez de Piñeros a don José de Ávalos, Intendente de la Provincia de Venezuela, Bogotá, 21 de abril de 1781, AGI, Caracas, 425.

29 Tapia, 2012, 42.

30 Aguilera, 1985, 133.

31 Informe confidencial de don Pedro de Berástegui a don José de Ávalos, Intendente de la Provincia de Venezuela, Barinas, 16 de septiembre de 1781, AGN, Capitanía General de Venezuela, Diversos, t. LVI. 
Mérida habían logrado varias plazas como Ejido, Bailadores, Estanques y Lagunillas.

El 24 de julio entre la una y las dos de la tarde entraron en la Plaza de dicho Mérida según le pareció más de seiscientos hombres de Estanques, Bailadores, la parroquia del Ejido y algunos de la Grita con escopetas, lanzas, flechas, sables, y algunos de garrote, y habiéndose tendido, y ocupado la Plaza de dicho Mérida el que los capitaneaba que lo era un F. Contreras que entró a Caballo dijo por tres ocasiones puesto en medio de su escuadrón: Viva nuestra Señora del Socorro, y nuestro Rey y Señor Carlos tercero a que respondieron los suyos ¡Viva!; y que sucesivamente dijo que muriese el mal gobierno que fue respondido por los mismos ¡muera! Que luego plantó en la Plaza dos horcas y dos banderas blancas, y mandó a toda la Ciudad pasase por debajo de dichas banderas a cuya orden concurrió todo el común que había venido a la novedad y que efectivamente hicieron la ceremonia de pasar por debajo de dichas banderas que es la muestra de unirse a su proyecto a cuyo acto no concurrieron el Cabildo ni las personas de distinción de dicha ciudad. ${ }^{32}$

Los «reinosos» - como se les llama también a los comuneros en la documentación - venían del Nuevo Reino de Granada hasta cierto punto motivados por la misma onda expansiva que, desde Perú, originó esta suerte de convulsión lineal, hasta llegar a la «raya entre Mérida y Trujillo», como refieren a la frontera entre las dos ciudades. El movimiento fue exitoso en el pueblo de La Grita ${ }^{33}$ (actual estado venezolano Táchira, fronterizo con Colombia), en Estanques y en Ejido de Mérida, dos pueblos conectados donde por fuerza tuvo que pasar Berástegui o, precisamente, donde tuvo que ser un comisionado sospechoso, a riesgo de ser presa de los reinosos y escapar por poco. Posiblemente ocultó la identidad de su cargo.

\section{Un movimiento más que popular}

La naturaleza popular de los comuneros, como hemos apuntado, no era absoluta. Parte de las elites locales se interesaron en el movimiento por la meridiana razón de la utilidad que suponía rebajar — o eliminar - algunos de los impuestos que afectaban sus caudales, igualmente el trasfondo antimonopolista de la propuesta reinosa convenía en cuanto a la siembra, explotación y comercio del tabaco. Por estos motivos la ciudad andina de

32 Informe confidencial de don Pedro de Berástegui a don José de Ávalos, Intendente de la Provincia de Venezuela, Caracas, 20 de septiembre de 1781, AGI, Caracas, 425.

33 Castillo Lara, 1974, 99. 
Mérida se convirtió en un lugar propicio para propagar la causa de los comuneros del Socorro. Un miembro activísimo de la élite merideña y rector pastoral de la ciudad vio esto con alarma. El presbítero Francisco Antonio de Uzcátegui — aliado de Berástegui en Mérida — apuraba el sermón desde el púlpito, intentando contener la ola comunera en su ciudad. Así lo relata la carta de un testigo:

Y habiendo en el año de ochenta transcendido las llamas de las populares sediciones del Nuevo Reino de Granada a algunos lugares de esta provincia se dedicó el D. Francisco Antonio con tanto esmero y exactitud por embarazar el que contagiasen a Mérida que no dejó medio prudente de cuantos le dictó su amor y fiel vasallaje al rey, Dios le guarde, anhelando siempre a su real servicio y a evitar a sus compatriotas tan fea nota, los exhortó en la Iglesia por edictos los cohonortó [sic], y en las privadas conversaciones les persuadió los motivos que les debían retraer de entrar en parte con los conmovidos y que estaban obligados a conservar los sentimientos de lealtad. ${ }^{34}$

No solo insistió desde el templo. Uzcátegui envió a su hermano, Juan Nepomuceno Uzcátegui, a buscar auxilio militar en Maracaibo. Este último, en una carta a Ábalos, acusó de negligente al cabildo merideño ante el avance de los «tumultuarios» del Reino de Santa Fe. ${ }^{35}$ Esta jugada de los Uzcátegui valió para que «invadieran mis haciendas habiéndose dado orden para que fuesen a robarla como lo hicieron con las de mi hermano Dn. Juan Nepomuceno deteniéndoles solo la ejecución al ser eclesiástico y temerse de excomunión». ${ }^{36}$ Esto le mereció al presbítero el preciado reconocimiento de las autoridades en Caracas y en la villa y corte, pero para Juan Nepomuceno, quien sí sufrió el saqueo de sus haciendas, sin la protección de la mitra, significó la persecución y la muerte de su esposa embarazada. En toda forma fue defraudado por el monarca, quien nunca hizo caso a sus peticiones, como el ascenso a capitán de milicias, el corregimiento de Mucuchíes o de Lagunillas, o para el empleo de teniente gobernador de Mérida.

Las noticias confusas, donde se entremezclaban personalidades y villanos, tuvieron que causar terror en Mérida. Asimismo, por la calidad de estas informaciones, el cálculo político que pudieron hacer los funcionarios reales tuvo que ser atolondrado e impreciso. Esa percepción ambigua se nota en Francisco Antonio Uzcátegui, cuando escribe:

34 Fuentes Bajo, 2008, 169.

35 Don Juan Nepomuceno Uzcátegui a su excelencia el Intendente de la Provincia de Venezuela don José de Ávalos, Pueblo de Mendoza, 13 de octubre de 1781, AGN, Intendencia de Ejército y Real Hacienda, t. XVI, f. 157.

36 Fuentes Bajo, 2008, 170. 
En el Reino del Perú el Cacique de la Provincia Grita que se nombra Don José Gabriel Tupac Amaru Ynca se ha sublevado con diez Provincias en las que cuenta como con doscientos mil hombres, y que se ha posicionado del Cuzco habiendo destruido una tropa de mil doscientos hombres [...] aquí se han fijado algunas papeletas como remitidas del Reino, creo, y estoy en lo cierto que aunque el Populacho, como gente de poca reflexión hace algún semblante menos agradable, pero la gente principal está muy obediente y dócil a la obediencia del Soberano. ${ }^{37}$

Ábalos le responde a Uzcátegui en una carta reparadora y consoladora alegando que él y el rey estaban velando por la integridad de sus vasallos, y para ello habían «acordado varias providencias favorables a estos vecinos que según manifestaran a VM mis comisionados D. Francisco de Arteaga y D. Pedro Berástegui acordando lo conveniente para que se hallen surtidos de tabaco, y chimó a precios cómodos y equitativos: y si a VM le pareciese que pueden dispensárseles otros alivios, le pido me lo manifieste». Asimismo, le aclaraba que las partes informativas que le habían llegado eran exageradas y en algunos casos falsas: «las noticias que me comunica relativas al Perú hay mucho de ponderación, y algo también de falso según las Papeletas y Relaciones circunstanciales que hemos recibido de aquellos parajes; pues ni el Indio levantado tiene tanta gente como se supone, ni se ha apoderado de la Ciudad del Cuzco la cual se mantenía con crecida guarnición esperando solo la llegada del Regente y del Inspector general de Milicias que iban de Lima en busca del Rebelde». ${ }^{38}$

\section{Un agente en el terreno}

Queda comprobado, por la aclaratoria de los hechos sobre el Perú contenida en la epístola anterior, la importancia que imponía un agente que sí supiera informarse, para luego saber transmitir la novedad más oportuna a sus superiores en situaciones de conjura y sedición. Una información exagerada era, en lo práctico, un sabotaje operativo. Por ello Berástegui era para Ábalos un agente fundamental en el terreno.

Uzcátegui organizó con Berástegui «y otros cortos Caballeros mis parientes» una suerte de operación política de exhortación a la sociedad

37 Informe de Francisco Antonio Uzcátegui al Intendente de la Provincia de Venezuela don José de Ábalos, Mérida, 6 de junio de 1781, AGI, Caracas, 425.

38 Carta de don José de Ábalos a don Francisco Antonio Uzcátegui, Caracas, 20 de septiembre de 1781, AGI, Caracas, 425. 
merideña para que se articulara contra las tentativas comuneras, sin embargo, no tuvieron éxito, «ya no es posible tomarle la rienda al desenfrenado vulgo, y esperan ansiosos a los tumultuantes reinosos». Y, ante esta situación, ambos acabaron por solicitar el envío de cien hombres, o «prenderán los reinosos fuego a toda esa Provincia». ${ }^{39}$ Unas semanas más tarde Ábalos - habiéndose enterado puntualmente de todo lo acaecido en Mérida por Berástegui, quien entonces se encontraba en Trujillo- escribirá a Uzcátegui para informarle que había dispuesto el Capitán General que pasen a esa ciudad cien hombres con sus correspondientes oficiales. ${ }^{40}$

El referido análisis de Berástegui sobre la situación en Mérida es uno de los motivos para que el intendente tenga de aval la indagación del químico y, a partir de ese informe, pueda tomar las decisiones como la de enviar un contingente militar. De otra forma, ¿por qué nombra a Berástegui en la carta a Uzcátegui como referente obligatorio? A Ábalos le llegaban los informes de sus altos funcionarios a lo largo de la provincia: de Uzcátegui y de Arteaga, desde Mérida; de Albuquerque, desde Maracaibo, y de Pumar, desde Barinas. Empero, se decanta por las noticias mucho más razonadas del navarro. Podríamos decir que eran informes de inteligencia militar. Las cartas del químico eran para Ábalos la garantía de un análisis de inteligencia, por lo que, basado en ellos, aclaraba confiadamente el escenario político. Tal y como había ocurrido con sus recomendaciones a partir de los experimentos con el tabaco, el urao y otros cultivos, Berástegui gozaba de un ingenio analítico que el intendente reconocía.

En su informe Berástegui le escribe a Ábalos que si en un principio Mérida se comportó como una plaza leal, ahora mismo observa que el lugar ha cambiado de posición: «lo demuestran en su ánimo, y algunas palabras que inadvertidamente producen, y los otros, o gente plebeya, que la considero más leal, sin duda por hallarse requeridos de estos con amenazas, están dispuestos a seguir el mismo partido». ${ }^{41}$ Infaliblemente, en esta carta reservada se entiende un trabajo de inteligencia: escuchar, observar las sutilizas, aparentar, penetrar, deslizarse, analizar e informar:

39 Carta de don Francisco Antonio Uzcátegui a don José de Ávalos, Intendente de la Provincia de Venezuela, Mérida, 18 de julio de 1781, AGI, Caracas, 425.

40 El Intendente de la Provincia de Venezuela, don José de Ábalos a don Francisco Antonio Uzcátegui, Caracas, 7 de agosto de 1781, AGI, Caracas, 425.

41 Informe reservado de don Pedro de Berástegui a don José de Ávalos, Intendente de la Provincia de Venezuela, Trujillo, 26 de julio de 1781, AGI, Caracas, 425. 
Si con cuidado se atiende a las conversaciones de las mujeres de mayor calidad producen sin reflexión lo que sin duda han oído hablar con gusto a sus maridos de las sublevaciones que esperan, igualmente los hijos de familia, niños de ambos sexos. Se puede inferir también con bastantes fundamentos que los de Mérida han tenido, y tienen comunicación oculta, con los sublevados de arriba, respecto de que aunque no transita el correo tienen cartas de la Ciudad de Pamplona, Villa del Socorro y otros pueblos lo mismo se infiere de los de esta Ciudad de Mérida. ${ }^{42}$

El químico navarro descubre los enmascaramientos políticos que aprovechan el caos reinante, «prueba de esto un Pedimento que el Procurador general de la referida Ciudad de Mérida presentó a aquel Cabildo dispuesto según estoy informado entre seis, o siete de los que aparentan más fidelidad, y ocultamente atizan el fuego de la sublevación». ${ }^{43} \mathrm{El}$ procurador de la ciudad ha huido, como relata Berástegui, por intentar un doble juego con el manejo político que hizo respecto al pago y a la exoneración del Estanco y los donativos. La plebe se dio cuenta de su movimiento y fue tras él. La ciudad se quedó sin administrador de justicia mientras todos esperaban a los reinosos.

Berástegui descubre también que el administrador de la Real Hacienda en Pamplona de Nueva Granada, el Dr. Bruno Castilla, es un doble agente. En primera instancia, este le había confiado al ilustrado lo que le había acontecido con el oidor y una comisión escoltada por cincuenta hombres de armas, dispuestos a aquietar a los comuneros en Pamplona. Refería que, en el camino, salieron al paso los rebeldes para impedir el tránsito de la comitiva, «con gran vigor» obligaron al oidor y sus acompañantes a esconderse en una casa cercana que incendiaron por varias partes para obligarlos a salir. Sin embargo, en manos de los rebeldes, el oidor fue tratado con el mayor respeto y veneración por parte de los reinosos, tanto así que fue con ellos a oír misa. Aunque lo secuestraron, lo trataban con suma consideración pero lo mantuvieron incomunicado. Según refiere Berástegui, el error del administrador - lo que le hizo tener su primera sospecha - fue la escasa seguridad que llevó la comisión, por ende, la pobre resistencia que pudo dar. A su juicio, al menos era muy sospechoso que desde un principio no hubieran planeado enfrentar a los sediciosos.

Berástegui no creía en las intenciones de Castilla y dudaba de su lealtad desde un principio. Le había dicho que pensaba ir a Maracaibo a dar cuenta sobre los sucesos de Pamplona al gobernador, pero el navarro

42 Idem.

43 Idem. 
consideró esto osado y le propuso que en lugar de ir a Maracaibo viajase a Caracas para informar allá sobre todo lo que ocurría en Santa Fe. Igualmente, le ofreció todas las comodidades para su desplazamiento, e incluso dinero suyo de su propia cuenta. A todo, Castilla «no aceptó y menos prosiguió el destino que me significó, se quedó en Mérida, y ahora se ha retirado a un Pueblo inmediato a dicha ciudad que llaman la Mesa cercano al Camino Real aparentando gran miedo a la gente que dicen vienen del Reino».

Berástegui descubrió que Castilla era uno de los confidentes de los sublevados «y que anda delante de ellos disponiendo los ánimos: la presura con que me insinuó iba apartándose de estos alborotos, el no haber aceptado los partidos que le hice, y el haberse quedado en Mérida y el esperar ahora a los sublevados como también en no haberse dado por entendido de lo que contra él produjo el referido Procurador de Mérida, en mi entender son motivos de alguna sospecha». Asimismo, revela a otro infiltrado, un tal «Don Fulano Cuellar», de quien narra cómo huyó de Pamplona por aquellos alborotos y que, por haberse negado a ser capitán de los sublevados - ya que los reinosos lo querían nombrar-, ahora quería pasar a Barinas hasta que se calmase la rebelión. Sin embargo, sabe Berástegui que Cuellar marchó a Trujillo: «ha pasado por dicha Jurisdicción en unas partes sembrando su fidelidad, y en otras introduciendo la peste que en el Reino se experimenta». ${ }^{44}$

Advertía el químico que los comuneros piensan repartir los papeles sediciosos no solo en la provincia de Maracaibo, sino lograr su distribución en Caracas para propagar la revolución en la capital provincial y crear el caos, todo ello, a la vez, como estrategia de sumar más gente, pues «siendo más el número de los culpados sea menor el castigo». Aseguraba Berástegui que toda Mérida está ocultamente sublevada, según sabe por los criados y peones con los que él anda, quienes le informan y «se explican» con más satisfacción. Recomendaba, por tanto, que se dispusiese de cincuenta hombres gobernados por un buen capitán para atemorizar a los nobles y a los sediciosos ocultos, y ante la incapacidad de motivar a la plebe, se tomasen automáticamente del «Partido de la Tropa».

Una de las estrategias de los reinosos, según Berástegui, era que al entrar debían asegurar oficios reservados firmados por el príncipe de Asturias, donde se promulgaba la abolición del Estanco del tabaco y el donativo. Como estos actuaban «sin atropellar la Ley de Dios», no cometen delito.

44 Idem. 
«Por todo lo cual y con reflexión a los exhortos, que en Mérida he practicado y el poco fruto que se sacó de ellos, me parece que aquí se debe empezar con el mayor rigor a fin de contenerlos y sujetarlos a las órdenes del Rey y sus Ministros». ${ }^{45}$

En contestación a su informe, Ábalos responde a su agente en el terreno que el capitán general ya dispuso de cien hombres de tropa para Mérida, y al menos cincuenta irían por Trujillo para poner orden. Esperaba que con esto se «contenga el incendio» $\mathrm{y}$, a la vez, le pedía a Berástegui «que esté muy a la mira de las ocurrencias de aquellos parajes, y me comunique prontos avisos de todo despachando a este fin los propios que le parezca con reserva y sigilo». ${ }^{46}$ Aquel era el capitán general y gobernador Luis de Unzaga, quien le escribió al intendente Ábalos confirmándole que «según verificaban las cartas que me remitió de D. Pedro de Berástegui y [el] Vicario de aquella ciudad [Francisco Antonio de Uzcátegui] hemos acordado destacar cien hombres de Infantería y treinta de Caballería para detener el fuego que tan de cerca nos amenaza con destino a dicha ciudad y de paso examinar la de Trujillo dos principales entradas para esta Provincia y la de Maracaibo». ${ }^{47}$ Destaca aquí la jerarquía de Berástegui en el marco estratégico de la crisis de los comuneros, así como el voto de confianza del alto mando provincial hacia el criterio del químico sobre las lides de contrainsurgencia.

No obstante, los encargos de Berástegui no rinden todavía el efecto esperado a pesar de la premura con que recomendó las acciones: «En Mérida continúan en sosiego sin la menor novedad», escribe Berástegui — desde el Tocuyo, el 10 de octubre de 1781 - a quien trata como «paisano y amigo» Francisco de Goicoechea. Esta carta en particular es un tanto críptica en cuanto a una información: advierte a Goicoechea que se encuentra enfermo y por tanto privado «de la tarea de la pluma», por lo que le pide que escriba él a Ábalos, pues «S.S. me avisa no haber recibido las mías del 22 del pasado, estas las dirigí a VM en un pliego, al mismo tiempo que le di noticias de mi libertad». ${ }^{48}$ Esta última noticia es muy llamativa, pues por ninguna otra referencia documental se sugiere que haya sido prisionero.

\footnotetext{
45 Idem.

46 Carta de don José de Ábalos, Intendente de la Provincia de Venezuela a don Pedro de Berástegui, Caracas 7 de agosto de 1781, AGI, Caracas, 425.

47 Carta del capitán general y gobernador don Luis de Unzaga al Intendente de la Provincia de Venezuela, don José de Ábalos, Caracas 8 de agosto de 1781, AGI, Caracas, 425.

48 Carta de don Pedro de Berástegui a don Francisco de Goicoechea, El Tocuyo, 10 de octubre de 1781, AGN, Intendencia de Ejército y Real Hacienda, t. XVI, f. 34.
} 


\section{El abastecimiento militar del Tocuyo}

Ahora bien, sí que es cierto que la sublevación comunera tomó por sorpresa a Berástegui en Mérida, en medio de los estudios químicos del urao y del salitre. Es común leer en la correspondencia cruzada entre las autoridades locales merideñas y caraqueñas, cuando refieren a Berástegui, cómo advierten que este se encontraba en sus experimentos en «las Lagunillas». Berástegui salió de Mérida, del pueblo de Lagunillas, a toda prisa, como si huyera hacia Trujillo, lugar donde los comuneros fueron parcialmente repelidos por el desapego a la causa reinosa, pero también por la manipulación e intrigas de sectores del cabildo que deseaban sacar partida del caos político y militar; ${ }^{49}$ y en alguna medida, por las artes políticas del abogado trujillano Antonio Nicolás Briceño, el único personaje claramente leal. En la carta a su paisano Goicoechea, el químico expone:

Se han hecho preparativos y proyectan partir para el campo pasado mañana, sin haber la menor necesidad, yo he puesto mis disimulados reparos pero no me han valido, todo es dirigido a desollar el erario cuya máxima no dudo hubiese un conocido a su partida de aquí, y hoy la siguen con tesón. Cardona no se ha contentado con lo hecho pues aún me promete grillos, sumamente sofocado me ves, pero no dude VM de mi constancia, aunque con el justo dolor de no poder manejar nada con acuerdo, conviene noticie VM al Sr. Intendente. ${ }^{50}$

«Cardona me promete grillos» es una obvia amenaza que sufre Berástegui. Sin embargo, no se trata de esta situación con el teniente de justicia mayor, Vicente Cardona, a lo que se refiere en su misiva a Ábalos con aquello de «le di noticias de mi libertad». Pues esta frase indica que posiblemente sufrió una reclusión o inminente peligro en manos de un enemigo más difícil que Cardona, como pudieron ser los comuneros. Vicente Cardona había apresado precisamente a Goicoechea, a la sazón administrador de la Real Hacienda, por discrepancias en el manejo de los fondos reales frente a la contingencia militar de los reinosos. Fue una corta reclusión en la casa del alcalde ordinario Miguel Betancourt, pues Ábalos lo fustigó por ello y le ordenó que le diese la libertad de inmediato. ${ }^{51}$

49 Cardoza, 2015, 131.

50 Carta de don Pedro de Berástegui a don Francisco de Goicoechea, El Tocuyo, 10 de octubre de 1781, AGN, Intendencia de Ejército y Real Hacienda, t. XVI, f. 34.

51 Carta de don José de Ábalos, Intendente de la Provincia de Venezuela al alcalde don Miguel Betancourt, Caracas, 17 de octubre de 1781, AGN, Intendencia de Ejército y Real Hacienda, t. XVI, f. 199. 
Esta información denota varios elementos. Por un lado, las desavenencias de cómo manejar el dinero ante la situación de los comuneros del Socorro es un tema que reluce en la documentación, pues a los ojos de Luis de Unzaga, capitán general y gobernador de Venezuela, la reacción de las autoridades locales ha sido tímida cuando no displicente. Unzaga critica la falta de mano firme y descuido, aquí se nota justamente como los paisanos Berástegui y Goicoechea creen que es un gasto innecesario el dinero utilizado - con auditoría mínima - en el apresto de las tropas, pues veladamente se ocultan segundas intenciones para fructificar estas incursiones como un modo de extracción de dinero y a la vez de tanteo de la cosa militar frente a los reinosos. Están al tanto del peligro de la sublevación comunera, pero son celosos con el erario que supone un despilfarro, un «desollamiento» de las arcas reales por preparar las tropas con propósitos grises.

En efecto, para Berástegui es suficiente que los sublevados vean las tropas de cerca «yo creeré que conforme se vayan arrimando las tropas marchará cada pobre a su casa», ${ }^{52}$ cada pobre seducido por la consigna comunera. La tarea del químico será entonces la logística del abastecimiento militar del Tocuyo (vigilaría de la manutención de ochocientos soldados preparados para la acción y estaría a la espera de un envío de pólvora y fusiles provenientes de Puerto Cabello), ${ }^{53}$ base de operaciones para realizar incursiones en Barinas y Trujillo. Desde el Tocuyo, para el navarro, la visión del conflicto toma mayores dimensiones. Una vez que llega a aquí, Berástegui analiza fríamente la situación de Trujillo, pues le hace saber a Ábalos que entrevé un juego de intereses entre las autoridades trujillanas y el peligro de que traicionen o, en todo caso, que se valgan del clima de zozobra y la cierta anarquía que impera en la región para sacar partido, como vender libremente el tabaco y el moó, sustituir anárquicamente a las autoridades de hacienda y dejar de pagar los demás derechos reales. Por ese motivo tenían preso a Goicoechea y acosaban a otros funcionarios de la Real Hacienda. De hecho, Berástegui se da cuenta de cómo aprovechaban el desconcierto los del cabildo, pues simulan una situación inevitable de guerra, movilizan a la gente a la «raya» entre Trujillo y Mérida, para aparentar una gran resistencia contra los comuneros, y justifican así el gasto

52 Carta de don Pedro de Berástegui al Intendente de la Provincia de Venezuela, don José de Ábalos, El Tocuyo, 5 de octubre de 1781, AGN, Intendencia de Ejército y Real Hacienda, t. XVI, ff. 86-87.

53 Asimismo, estaba a la espera de 2000 pesos que se enviaron de Puerto Cabello para los gastos de este tipo. 
con el desorden necesario que encubre el manejo a discreción de las reales cajas y de las mercancías vedadas por el monopolio del tabaco.

Ante esta situación, Berástegui propone que ahorquen de forma ejemplarizante a los facciosos del cabildo trujillano, a Sancho Briceño y a Felipe Coronado, y dejar apostado un destacamento de cincuenta hombres de tropa venidos de Maracaibo. El navarro asegura que puede mantener en el Tocuyo quinientos soldados por seis meses - mandó a traer de un hato sesenta reses para la tropa-, y a dicho fin, para la causa del rey, se le había embargado los víveres necesarios a los vecinos del Tocuyo. Él sabe cómo animar a la gente para que respalden su plan. Calcula que con los alimentos de esa jurisdicción se puede mantener un cuerpo de quinientos hombres por un año para contener los pueblos de la provincia de Maracaibo ante la tentación de los comuneros. Cuando Berástegui habla de Maracaibo incluye a Mérida. ${ }^{54}$

En cuanto a la latente traición de Trujillo, piensa que no tiene sentido mover las milicias de La Guaira y Puerto Cabello por la guerra actual con Inglaterra, dado que para poner orden en Trujillo y los demás pueblos sublevados, es necesario un cuerpo militar de quinientos efectivos venidos de Barquisimeto, Araure, el Tocuyo y Valencia, sin descuidar los puertos de la amenaza británica. Plantea también movilizar «un par de docenas de pedreros, de tres a cuatro cañones de a seis», perfectamente transportables en bestias.

Informa que lo mismo aconsejó desde Mérida al teniente de justicia de Barinas, José Ignacio del Pumar, que a este con cincuenta hombres le basta para frenar cualquier incursión de los reinosos, pues el camino de paso entre Mérida y Trujillo es tan estrecho que permite una maniobra efectiva de contención. Sin embargo, advierte, es necesario enviar municiones y dos oficiales. Por último, observa que un grave error estratégico fue cometido por diferentes tenientes de justicia de estas regiones, por el hecho de no impedir el paso de los papeles (propaganda en términos de hoy) que los reinosos habían esparcido exitosamente, sembrando dudas en el sistema y haciendo creer a las distintas poblaciones que son objetivo potencial de la invasión comunera.

54 La unidad territorial de la provincia de Maracaibo se da desde 1607 al crearse el corregimiento de Mérida a cuya jurisdicción pasaron la propia Mérida, La Grita, San Cristóbal, San Antonio de Gibraltar y Barinas. Este corregimiento se elevó en 1625 a provincia y por la real cédula del 31 de diciembre de 1676 se incorporó la ciudad de Maracaibo y sus alrededores al darse la orden a los gobernadores residir allí, a partir de ese hecho Maracaibo pasó a ser provincia de Maracaibo. 


\section{Es preciso que trabaje el verdugo para que no vuelva a encenderse esta hoguera}

La idea final del análisis de inteligencia de Berástegui es que si se hacen las cosas como él plantea toda la provincia se apaciguará. Eso sí, «es preciso que trabaje el verdugo para que no vuelva a encenderse esta hoguera, una docena de ejemplares harán callar a todos: los sublevados entre los Republicanos, mal armados, y falta de muchas cosas precisas para conservarse por mucho tiempo unidos si se les empieza con vigor a perseguir». ${ }^{55}$ Con todo y con eso, no deja de vincular su labor de inteligencia militar con informes para la explotación agrícola. Así lo hace saber, por vía de Juan Bautista Zarandia, a quien encarga que haga llegar al intendente Ábalos un «plan de los frutos que se cosechan en las jurisdicciones de Mérida, La Grita y San Cristóbal». ${ }^{56}$ En la carta citada, Berástegui informa la buena nueva de que los rebeldes en Mérida y Trujillo se han dispersado un poco, y que el tan esperado ataque a Trujillo no se dio. Interesa en particular la afirmación de que «siempre he dicho a VS la fidelidad de este vecindario», en referencia al Tocuyo. Y así menciona cómo la llegada de doscientos hombres para reforzar la plaza tocuyana y Barinas será «bastante para que no se haga el más mínimo movimiento de infidelidad, y ya de arriba no pasan tantas noticias y cartas con las que inficionaban estas gentes». ${ }^{57}$

Tras estos sucesos, el intendente Ábalos habría de remitir un minucioso informe a José de Gálvez fechado el 22 de septiembre de 1781 describiendo, desde el principio, los eventos de la rebelión y, sobre todo, la respuesta que habían dado hasta la fecha sus funcionarios desplegados en el terreno de los acontecimientos. ${ }^{58}$ Por la conexión entre el virreinato de la Nueva Granada con Maracaibo y Mérida, los principales informantes de la rebelión fueron Berástegui, Uzcátegui y Arteaga; sin embargo, Berástegui es el agente cuyas fuentes predominarán y así lo hace saber a Gálvez. Será, además, Berástegui quien coordine y enlace los movimientos de tropas — para auxiliar a Mérida y Trujillo— con otras regiones cercanas, como Carora, el Tocuyo y Barquisimeto.

55 Carta de don Pedro de Berástegui al Intendente de la Provincia de Venezuela, don José de Ábalos, El Tocuyo, 23 de agosto de 1781, AGI, Caracas, 425.

56 Carta de don Pedro de Berástegui para don Juan Bautista Zarandia, El Tocuyo, 19 de octubre de 1781, AGN, Intendencia de Ejército y Real Hacienda, t. XVI, ff. 214-215.

57 Idem.

58 Informe de don José de Ábalos a don José de Gálvez, Caracas 22 de septiembre de 1781, AGI, Caracas, 425 . 
Ábalos hace saber a Gálvez que la situación sigue siendo peligrosa para el orden en la provincia, pues conoce de buena mano que los reinosos planean sublevar el otro extremo del país bajando por el río Meta para cruzar al Orinoco y encontrar el apoyo inglés, quienes habían apostado en el río Amazonas embarcaciones de guerra, para lo cual sugiere que se destine una lancha armada con pedreros y cañón a la proa que pueda impedir el paso de los sublevados «que no tienen fuerzas iguales que oponer, porque carecen absolutamente de artillería». ${ }^{59}$

En una epístola del mes de agosto Berástegui ya le insinuaba a Ábalos hechos que forman parte de una discusión historiográfica importante: el continuo desacuerdo entre los ayuntamientos y cabildos —el poder localy la real Hacienda — que junto a la Intendencia y la Capitanía General ejercen el poder central - propician un quiebre de mando que es además una crisis de gobernabilidad en esta parte de los reinos de ultramar: «se viene en claro conocimiento de la tibieza y lentitud, y aún poca fidelidad con que han procedido los Ayuntamientos, y tenientes de justicia mayores de los Pueblos amenazados [...] las resoluciones que considerase adecuadas, y que si se han tomado algunas ha sido a instancias de los Ministros de la Real Hacienda en las Ciudades de tierra adentro, y del Intendente en la capital ${ }^{60}$.

Los reinosos fueron dispersados en Mérida ante la numerosa fuerza expedicionaria que ocupó la ciudad. La conocida Expedición de la Frontera que a marchas forzadas tardó en llegar casi dos meses, sin disparar un solo tiro, fue suficiente para apaciguar el lugar. ${ }^{61}$ La experiencia y el trago amargo que sufrieron las autoridades gubernativas de la provincia obligaron a establecer un cuerpo de tropas veteranas y milicias disciplinadas al mando del coronel merideño Juan de Salas. Las milicias no entraron en combate contra los reinosos, pero actuaron posteriormente en persecuciones, detenciones, capturas y embargos a los implicados. Esto ayuda a comprender que la presencia militar de la capitanía general venezolana era inorgánica y desestructurada. La guerra con Inglaterra concentró la defensa de los puertos, sin embargo, la lentitud de la respuesta contundente, las largas burocráticas dadas en cartas de las máximas autoridades hacia los mandos locales revelan displicencia e indiferencia. En la carta citada de Berástegui a Ábalos, de agosto de 1781, se entrevé que las autoridades políticas locales no eran del todo confiables.

59 Idem.

60 Carta de don Pedro de Berástegui al Intendente de la Provincia de Venezuela, don José de Ábalos, El Tocuyo, 23 de agosto de 1781, AGI, Caracas, 425

61 Cardoza, 2012, 130-136. 


\section{Epílogo}

Durante la rebelión el intendente Ábalos contó verdaderamente con los funcionarios de la Real Hacienda, es decir, el poder no era monolítico, no era compacto ni vertebrado, la única amalgama era la presencia simbólica del rey y el peso de la ley cuando era irrecusable. Los reinosos no lograron hacer más daño porque no sabían que de hecho podían hacerlo. Consumadas su obligaciones logísticas, administrativas, políticas y de inteligencia, el intendente le pidió a Berástegui que inspeccionase las minas de Aroa ${ }^{62}$ a unos 200 kilómetros del Tocuyo, dos días de camino. No se conoce mucho más de su paso por la administración del poder colonial, ni qué destino le deparó el futuro antes de su muerte, que lo alcanza en Madrid en 1785, como se sabe por la noticia contenida en la real orden del 5 de noviembre de $1785 .{ }^{63}$ El nuevo intendente, Francisco de Saavedra, llegaría en 1783 a Venezuela.

La sustitución de Ábalos pudo ocurrir, entre otras razones, por la forma en que manejó la rebelión comunera. En una esquela, desde San Ildefonso, del 24 de agosto de 1782, «se le previenen [a José de Ábalos] varias observaciones, que quiere S.M. guarda y cumpla en todo, tanto en punto a su régimen y gobierno, como el que use en sus escritos de un estilo sencillo y moderado». ${ }^{64}$ ¿Se había ganado la aversión del monarca y su caída en desgracia fue producto del análisis de los hechos que se hizo en la villa y corte? A Ábalos, tal vez, le faltó tacto al momento de escribir a Madrid, y pasó ante la mirada del rey y los suyos como un funcionario impulsivo. Sin embargo, como hemos leído, en los cruces epistolares con Berástegui era amable, considerado y dista de parecer una autoridad soberbia, al menos con su subordinado de más confianza. Con todo, Ábalos sí se habría granjeado cierta ojeriza desde Madrid por su severidad y duro temperamento en Caracas, ya había sufrido duras oposiciones y críticas a su desempeño. Fueron varias las peticiones de Ábalos a la corte para licenciarse en sus funciones y regresar a España, antes de todas las crisis, debido a padecimientos de salud y cansancio. ${ }^{65}$ También es verdad que venían los tiempos del finiquito

62 Carta del Intendente de la Provincia de Venezuela, don José de Ábalos a don Pedro de Berástegui, Caracas, 17 de octubre de 1781, AGN, Intendencia de Ejército y Real Hacienda, t. XVI, ff. 204-205.

63 Arcila Farías, 1977, 328.

64 Petición de don José de Ábalos, Intendente de la Provincia de Venezuela, elevada a Su Majestad, don Carlos III, Madrid, 10 de septiembre de 1782, AGI, Caracas, 425.

65 Zubiri, 1988, 295. 
de la Real Compañía Guipuzcoana de Caracas y la Corona necesitaba un negociador, un hombre con más tacto, menos severo y más político, como en efecto resultó ser Francisco de Saavedra, el sevillano ilustrado, el segundo intendente de Caracas. ${ }^{66}$

Pedro de Berástegui, máximo aliado de Ábalos, no logró insertarse en el proyecto de Saavedra. Podríamos suponer, no sin temeridad, que el nivel de confianza que gozó el químico navarro en el gobierno de José de Ábalos mermó sus posibilidades políticas con la nueva administración, pues la visión de gobierno que traía Saavedra era muy contraria a la de su antecesor, quien fustigó el monopolio la Real Compañía Guipuzcoana y se ganó también la antipatía de una nueva élite criolla que había crecido a expensas de ese monopolio y gozaban, en efecto, de poder en la provincia. Saavedra planeaba gobernar con esta élite y conciliar los intereses de la Compañía Guipuzcoana con el gobierno español para lograr un finiquito en buena lid. ${ }^{67}$

El nuevo intendente Saavedra le escribiría a José de Gálvez en 1783 exponiendo que «apenas hay un palmo de terreno en toda aquella Provincia que no sea a propósito para el tabaco». ${ }^{68}$ En alguna medida, ese paisaje que captura la atención de Saavedra fue un logro científico y administrativo de Pedro de Berástegui. Saavedra se encuentra también con una provincia pacificada, que poco antes de su llegada ardía por la fiebre comunera, de la que Berástegui fue parte de la solución de la crisis de los reinosos del Socorro y de los comuneros de Mérida. Por las lecturas periféricas hechas en sombras documentales, así como por inferencia lógica, Berástegui y Saavedra tuvieron que conocerse, pues el sevillano comenta sobre su muerte y recibe instrucciones respecto a darle un cargo en la administración real a un sobrino suyo que quedó en Venezuela, en correspondencia por los méritos y servicios del navarro. ${ }^{69}$

69 Arcila Farías, 1977, 329. 


\section{Referencias bibliográficas}

Aguilera Peña, Mario, Los Comuneros: guerra social y lucha anti-colonial, Bogotá, Universidad Nacional de Colombia, 1985.

Andreo García, Juan, «El Estanco del tabaco en Venezuela durante la etapa de Don Esteban Fernández de León, 1779-1803», Cuadernos de Investigación Histórica, 11, Madrid, 1987, 89-110.

Andreo García, Juan, «La última fase del reformismo en América: Venezuela y los últimos intentos de reforma económica, 1790-1803», Estudios Románicos, 6, Murcia, 1989, 1505-1520.

Andreo García, Juan, La Intendencia en Venezuela. Don Esteban Fernández de León Intendente de Caracas. 1791-1803, Murcia, Universidad de Murcia, 1991.

Andreo García, Juan, «La Intendencia Indiana. Análisis historiográfico y perspectivas», Contrastes. Revista de Historia, 9:10, Murcia, 1997, 237-257.

Anes, Gonzalo, «Las expediciones científicas españolas en el siglo XVIII», en Escudero, José Antonio (coord.), Españoles de ambas orillas. Emigración y concordancia social, Madrid, Sociedad Estatal Lisboa 98, 1998, 1-23.

Arcila Farías, Eduardo, El Estanco del Tabaco en Venezuela (1779-1833), Caracas, Universidad Central de Venezuela, 1977.

Briceño-Iragorry, Mario, Tapices de Historia Patria. Ensayo de una morfología de la cultura colonial, Caracas, Ediciones del Congreso, 1989.

Cardoza Sáez, Ebert, «Los Comuneros de Mérida: Las milicias entre la lealtad y la insurgencia (1781-1810)», Historia Caribe, 27, Barranquilla, 2015, 103-140.

Cardozo Uzcátegui, Alejandro, Los Mantuanos en la Corte Española. Una relación cisatlántica (1783-1825), Bilbao, Universidad del País Vasco/Euskal Herriko Unibertsitatea, 2013a.

Cardozo Uzcátegui, Alejandro, «El Círculo de Saavedra: amistad, lobby y poder de los venezolanos a finales del setecientos español 1783-1799», Pasado y Memoria, 12, Alicante, 2013b, 11-53.

Castillo Lara, Lucas Guillermo, La Grita, una ciudad que grita su silencio: historia del Espíritu Santo de la Grita, Caracas, Ediciones del Congreso, 1974.

Codazzi, Agustín, Resumen de la geografía de Venezuela, París, Imprenta de H. Fournier y Compañía, 1841.

Dekker, Rudolf, Jacques Presser's Heritage: Egodocuments in the Study of History, Rotterdam, Erasmus Universiteit Rotterdam, 2002.

Fuentes Bajo, María Dolores, «Vivir en tiempos de crisis. Mérida (Venezuela), 1781-1799», Minius: Revista do Departamento de Historia, Arte e Xeografía, 16, Vigo, 2008, 163-180.

García Yépez, Janette y Rodríguez Rojas, Pedro, «El Tocuyo: región Histórica», Terra. Nueva Etapa, 26:40, Caracas, 2010, 121-146. Disponible en: http://saber. ucv.ve/ojs/index.php/rev_terr/article/view/210 [Consultado: 30/05/2021]. 
Izard, Miquel, La agricultora venezolana en una época de transición, 1777-1810, Separata del Boletín Histórico de la Fundación John Boulton, Caracas, Italgráfica, 1972.

López Cantos, Ángel, Don Francisco de Saavedra, segundo intendente de Caracas, Madrid, Consejo Superior de Investigaciones Científicas, 1973.

Nieto, Mauricio, Remedios para el Imperio: Historia natural y la apropiación del Nuevo Mundo, Bogotá, Universidad de los Andes, 2019.

Pacheco, José Germán, Agricultura, modernización y ciencias agrícolas en Venezuela. De la ilustración borbónica a los ilustrados del gomecismo, 17701935, Caracas, Universidad Central de Venezuela, 2008.

Parra Pardi, María Elena, «Berástegui, Pedro de», Diccionario de Historia de Venezuela, I, Caracas, Fundación Polar, 1997, 417-418.

Tapia, Francisco, Los Comuneros de Mérida, Caracas, Editorial La Estrella Roja, 2012.

Zubiri, María Tersa, «José De Ábalos, Primer Intendente de Venezuela (17771783)», Boletín Americanista, 38, Barcelona, 1988, 287-297. 